
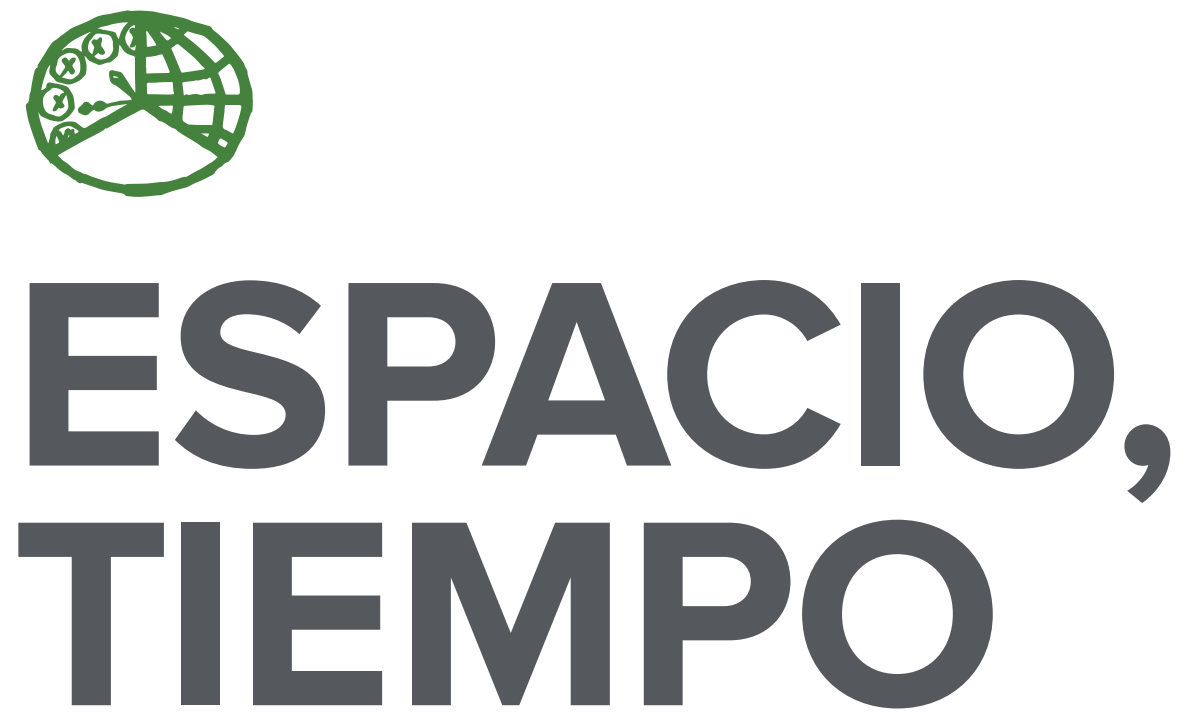

AÑO 2020

ISSN 1130-2968

E-ISSN 2340-146X
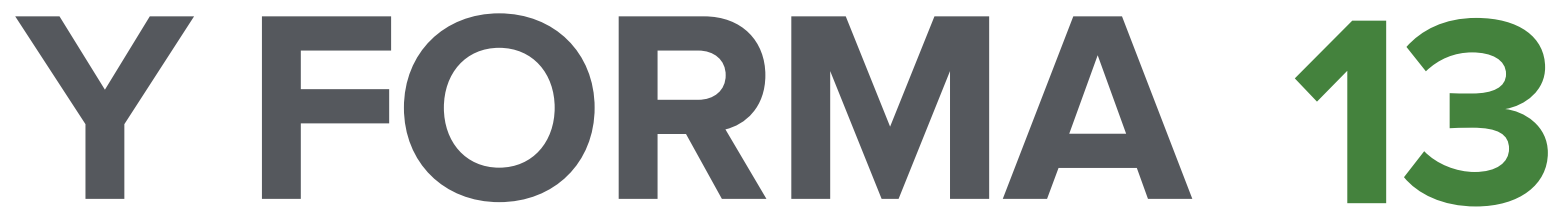

SERIE VI GEOGRAFÍA

REVISTA DE LA FACULTAD DE GEOGRAFÍA E HISTORIA 


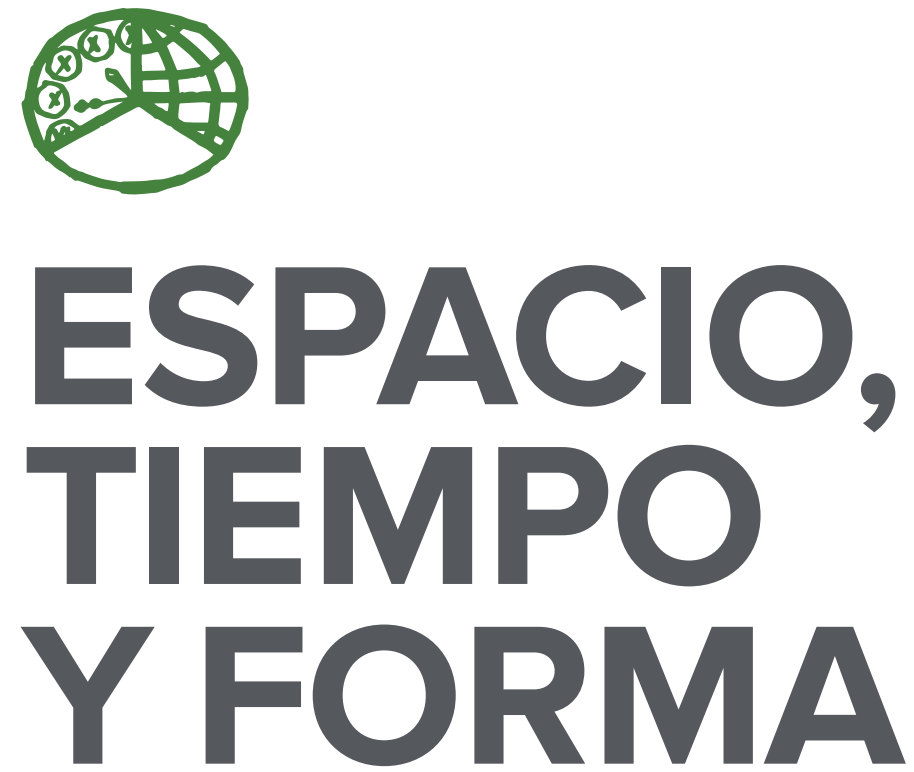

AÑO 2020

ISSN 1130-2968

E-ISSN 2340-146X

SERIE VI GEOGRAFÍA

REVISTA DE LA FACULTAD DE GEOGRAFÍA E HISTORIA

DOI: http://dx.doi.org/10.5944/etfvi.13.2020

\section{UחED}

UNIVERSIDAD NACIONAL DE EDUCACIÓN A DISTANCIA 
La revista Espacio, Tiempo y Forma (siglas recomendadas: ETF), de la Facultad de Geografía e Historia de la UNED, que inició su publicación el año 1988, está organizada de la siguiente forma:

$$
\begin{aligned}
& \text { SERIE I - Prehistoria y Arqueología } \\
& \text { SERIE II - Historia Antigua } \\
& \text { SERIE III - Historia Medieval } \\
& \text { SERIE IV - Historia Moderna } \\
& \text { SERIE V - Historia Contemporánea } \\
& \text { SERIE VI - Geografía } \\
& \text { SERIE VII - Historia del Arte }
\end{aligned}
$$

Excepcionalmente, algunos volúmenes del año 1988 atienden a la siguiente numeración:

$$
\begin{aligned}
& \mathrm{N}^{\circ} 1 \text { - Historia Contemporánea } \\
& \mathrm{N}^{\circ} 2 \text { - Historia del Arte } \\
& \text { N. }{ }^{\circ} 3 \text { - Geografía } \\
& \mathrm{N} .^{\circ} 4 \text { - Historia Moderna }
\end{aligned}
$$

ETF no se solidariza necesariamente con las opiniones expresadas por los autores.

\author{
UNIVERSIDAD NACIONAL DE EDUCACIÓN A DISTANCIA \\ Madrid, 2020 \\ SERIE VI $\cdot$ GEOGRAFÍA N. ${ }^{\circ} 13,2020$ \\ ISSN $1130-2968 \cdot$ E-ISSN 2340-146x \\ DEPÓSITO LEGAL \\ $M-21.037-1988$ \\ URL \\ ETF VI - GEOGRAFÍA $\cdot h t t p: / / r e v i s t a s . u n e d . e s / i n d e x . p h p / E T F V I$ \\ DISEÑO Y COMPOSICIÓN \\ Carmen Chincoa Gallardo · http://www.laurisilva.net/cch \\ Impreso en España · Printed in Spain
}


IMÁGENES Y PALABRAS .

PICTURES AND WORDS 



\title{
ETIOPÍA: RECORRIDO POR ALGUNOS PAISAJES NATURALES Y CULTURALES
}

\author{
Carlos J. Pardo Abad
}

Recibido: 06/05/2019 - Aceptado: 06/05/2020

DOI: http://dx.doi.org/10.5944/etfvi.13.2020.27453

Etiopía es un país fascinante situado en la zona conocida como "Cuerno de África». Con una superficie superior a I,I millones de $\mathrm{km}^{2}$ y una población no del todo conocida por los problemas de recuento censal propios de los países subdesarrollados, pero que podría rondar los I05 millones de habitantes, es un país federal que engloba culturas y lenguas diferentes, paisajes deslumbrantes y monumentos poco reconocibles inicialmente como del continente africano. La visita al país, que tuve la oportunidad de realizar en abril-mayo de 2019, me aportó una de las experiencias más intensas en mi dilatada carrera como viajero.

Su situación geográfica en medio del gran Rift Valley le otorga unos rasgos naturales espectaculares, con lagos, fracturas de gran recorrido, volcanes activos y extinguidos y unos suelos de color pardo oscuro que delatan su origen y evolución. Volcánico es el denominado macizo etíope, extensa región montañosa que supera en prácticamente todos los puntos los I.500 msnm y alcanza la mayor altura del país en Ras Dashen (4.553 msnm), siendo el cuarto pico más alto de todo el continente. Es una zona fría y lluviosa por la altura, con vegetación endémica y especies animales que solo se pueden encontrar en esta parte de África. Junto al volcán activo Erta Ale y el área geotermal de Dallol, ambos en la gran depresión de Afar, y los lagos distribuidos de manera lineal a lo largo del Rift Valley, es el principal recurso turístico de tipo natural de Etiopía. Desde el año 1978 toda el área de las denominadas Montañas Simien está declarada patrimonio de la humanidad por la UNESCO (Figura I).

Hacia el este las alturas del macizo etíope descienden bruscamente, hasta enlazar con la depresión de Afar. En esta depresión se encuentra el lago Assal, que está a -I55 msnm y constituye el punto más bajo de toda África. Es una zona peligrosa para el turista y de condiciones climáticas extremas, pero del mayor interés geográfico por ser el resultado de la separación geológica de las placas tectónicas africana y arábiga. Esta separación se mantiene aún activa, lo que rasga el territorio y lo fractura de forma que la corteza es muy débil y delgada, permitiendo la existencia de un volcanismo activo espectacular. Algunos volcanes, como el Erta Ale, son el destino de numerosos turistas científicos militarmente protegidos. Todo este territorio es el resultado de una actividad tectónica que está partiendo el continente africano en dos y acabará ocasionando la definitiva invasión del mar Rojo. Hacia el sureste

1. Departamento de Geografía, Universidad Nacional de Educación a Distancia (UNED). cjpardo@geo.uned.es 


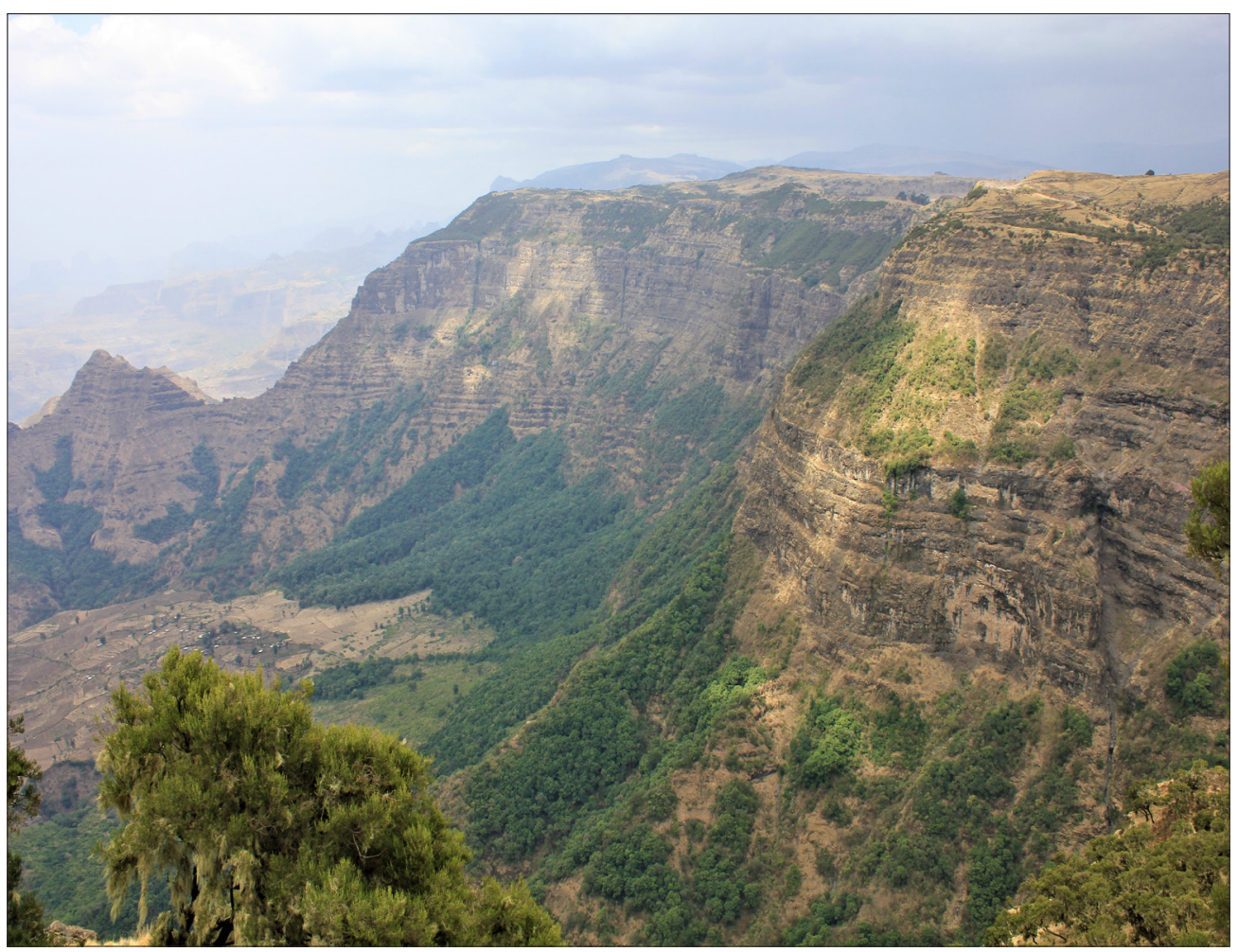

FIGURA 1. PARQUE NACIONAL DE LAS MONTAÑAS SIMIEN. Fotografía del autor

del país se encuentra el gran desierto de Ogadén, en la frontera con Somalia. Es una extensa zona desértica y poco habitada, de religión musulmana y con lenguas de origen somalí.

Volviendo nuestra mirada a la depresión de Afar, tenemos que recordar que la zona es más conocida si cabe por los restos de homínidos. En efecto, es el lugar de aparición de Lucy, un espécimen de Australopithecus Afarensis de enorme valor por lo que representa de ancestro del género Homo. Una reproducción se encuentra hoy en día en el Museo Nacional de Addis Abeba, junto a otros fósiles originales encontrados en la misma zona. Este museo es una de las principales visitas turísticas de la capital etíope y emblema de lo que representan sus fósiles como eslabón hacia los orígenes de la humanidad.

La naturaleza etíope es espectacular, pero su historia es fascinante. Es el único país cristiano de su entorno y su cristianismo es muy primitivo y judaizante en muchos de sus rasgos. Fue el segundo Estado después de Armenia en incorporar el cristianismo como religión oficial, existen numerosas iglesias y monasterios diseminados por toda la mitad norte del país, cuyo origen se remonta a la Edad Media, y el cristianismo ortodoxo convive armónicamente con el islam, religión esta última mayoritaria en el este y sur. Todo ello constituye un amplio elenco de elementos propios, vinculados en su mayor parte con la religión, que definen un sentimiento colectivo muy particular arraigado en la historia y las tradiciones.

Tradiciones vinculadas, además, a algunos movimientos espirituales como el rastafari. De origen jamaicano por sus vínculos nacionales con el esclavismo 


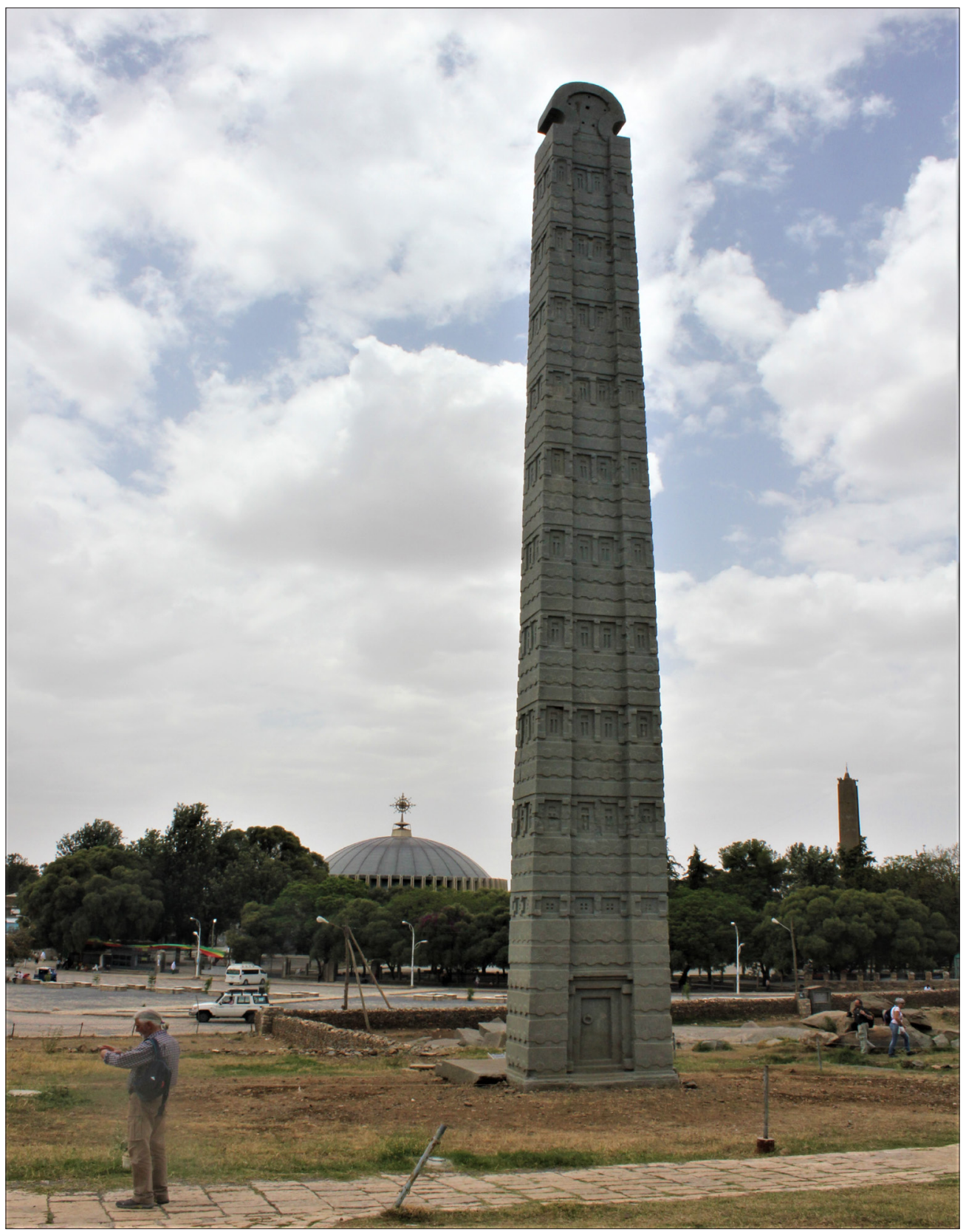

FIGURA 2. ESTELA FUnERARIA DE AKSUM. Fotografía del autor.

africano, se inició en la década de i930 y tomó como base de partida los que podrían considerarse como presupuestos panafricanistas y afrocéntricos y al emperador etíope Haile Selassie I por su carácter mesiánico. En la ciudad etíope de Shashamane existe una importante comunidad rastafari en el denominado «barrio jamaicano», concesión que Haile Selassie I hizo en I948 a toda la diáspora africana que quisiera volver al continente en agradecimiento al apoyo recibido contra las tropas italianas en la segunda guerra ítalo-etíope. 
El país fue convertido al cristianismo en los siglos $\mathrm{IV}$ y $\mathrm{V}$ por monjes procedentes de Egipto y Siria, encontrando un camino bastante allanado por los antiguos contactos existentes entre Etiopía y Tierra Santa. Este hecho explica que muchos rasgos del cristianismo etíope sean judaizantes y estén próximos a las tradiciones del juadaismo: a los niños se les practica la circuncisión, el sábado es el segundo día sagrado de la semana (casi más importante que el propio domingo) y en las iglesias hay siempre un espacio reservado para una reproducción del Arca de la Alianza. Rasgos que enlazan con la leyenda del origen israelita de la monarquía etíope, ya que cuenta la tradición que Menelik I, el mítico primer rey de Etiopía, era hijo de la reina de Saba y del rey Salomón.

El hecho es que la fe cristiana se difundió pronto por el país y Jerusalén se convirtió en lugar preferente de peregrinación y casi la única ventana al mundo que tenían los etíopes. La iglesia etíope presenta una historia muy prolongada y unas características fascinantes. Es única por el ámbito geográfico en el que adquiere protagonismo y se expande. Es copta en términos de teología y ritos debido a las influencias de la iglesia alejandrina de Egipto (con quien ha mantenido permanentes luchas de poder hasta su constitución como iglesia autocéfala tras su escisión jerárquica del patriarca copto de Alejandría en 1959). No reconoce el Concilio de Calcedonia del año 45I, cuyas definiciones dogmáticas sí fueron reconocidas como infalibles por las iglesias católica y ortodoxa. Además, la iglesia etíope es monofisita, es decir, admite en Cristo una sola physis o naturaleza. En definitiva, es una mezcla apasionante de tradición, devoción e identidad nacional que quizá no esté presente en ninguna otra iglesia cristiana.

Aksum (o Axum), en el norte de Etiopía y casi limítrofe con Eritrea, es el comienzo de todo, es el inicio de Etiopía. Allí se instalaron diversas poblaciones procedentes del sur de Arabia, que atravesaron el mar Rojo y se instalaron aquí para terminar fundando el reino más próspero al sur del Egipto faraónico: el reino axumita. Este reino abrazó el cristianismo en el siglo IV, muy vinculado a la leyenda de la reina de Saba y la custodia del Arca de la Alianza. Pronto se convirtió en una pieza geoestratégica fundamental para el control del comercio marítimo entre Europa y Asia. En esto se basaron su fortaleza y riqueza, y la construcción de edificios espectaculares. Un ejemplo son las estelas funerarias a las afueras de la ciudad, en un recinto declarado por la UNESCO como patrimonio de la humanidad (Figura 2).

Desde Aksum se extendió el cristianismo por el norte y centro de la actual Etiopía. Se fundaron nuevas iglesias, nuevos monasterios, a veces rupestres en medio de la montaña y en medio de cuevas y grandes oquedades. Existen muchos conjuntos de enorme valor artístico y cultural, con profusión de pinturas murales de vivos colores y figuras naíf marcadamente etíopes. En la actualidad son el destino de un turismo incipiente y aún minoritario, que el país quiere impulsar como fuente de ingresos y entrada de divisas.

El siglo XII representa la culminación de la ortodoxia etíope. El centro de gravedad se traslada hacia el sur, a la ciudad de Lalibela. En ella encontramos un conjunto extraordinario y único en el mundo de doce iglesias monolíticas excavadas en la roca, destino de un peregrinaje nacional que aún se mantiene en la actualidad. Fueron construidas durante el reinado de Lalibela (de ahí el nombre de la ciudad) 

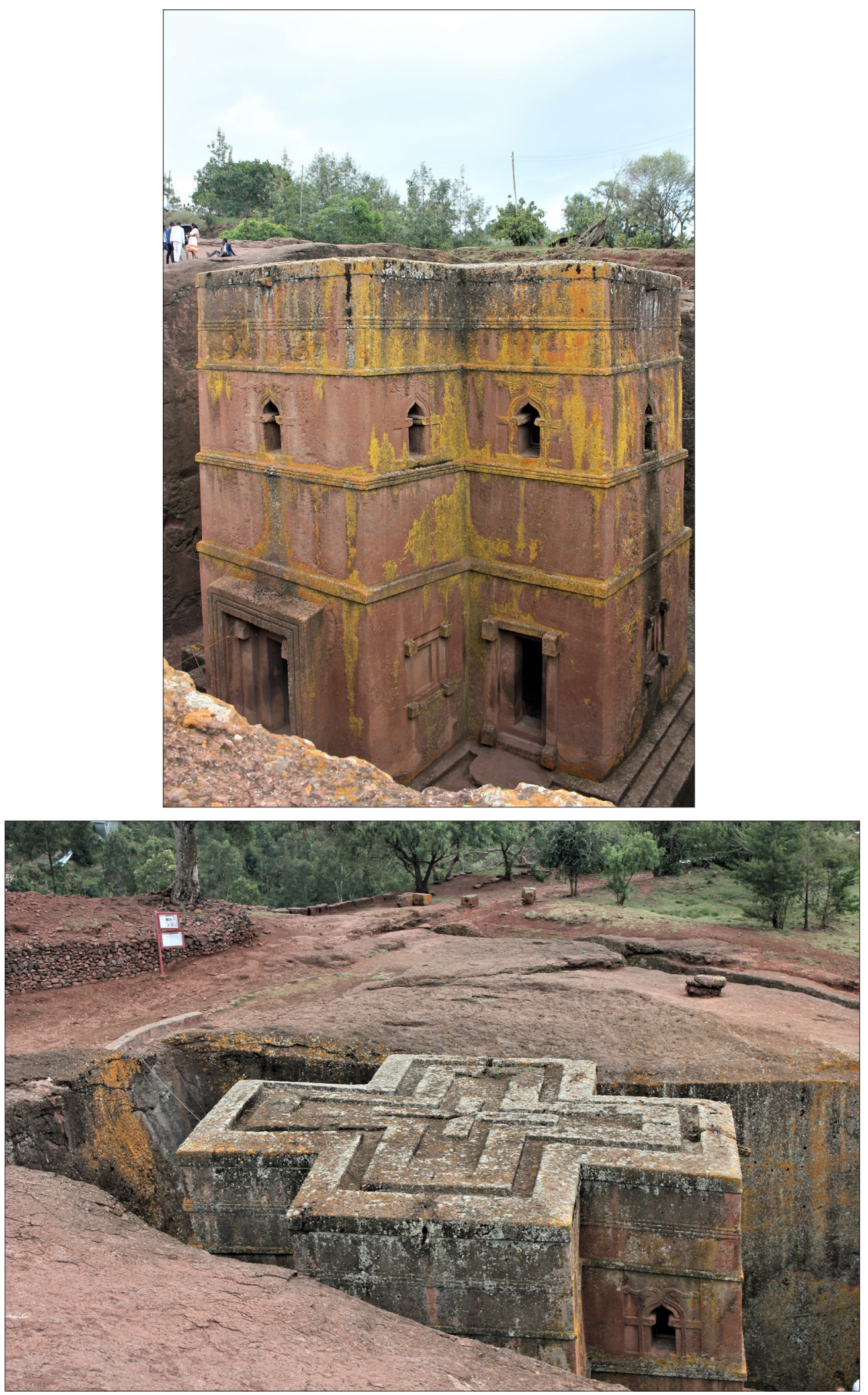

FIGURAS 3 Y 4. IGLESIA DE SAN JORGE EN LALIBELA. Fotografías del autor 
para sustituir las peregrinaciones a Jerusalén cuando estas quedaron bloquedas por la toma de la Ciudad Santa por los musulmanes. Esto indica la fortaleza del sentimiento religioso en Etiopía y el afán por mantener, en las más duras condiciones, la fe y las tradiciones vinculadas.

La visita a este conjunto de iglesias excavadas sorprende y refleja los niveles técnicos y artísticos alcanzados también en el continente africano. Sobrecogen, empequeñecen al turista y lo trasladan a tiempos remotos y ya ignotos para los occidentales. Son esculturas arquitectónicas o arquitecturas escultóricas, como se prefiera, porque son monolíticas, de una única pieza, nacidas tras ser horadada palmo a palmo la roca del monte. Representan a Jerusalén y para ello era necesario también excavar un largo talud que representara simbólicamente al río Jordán (aunque, en la realidad, el Jordán no atraviese la Ciudad Santa). Algo simplemente espectacular. La iglesia más conocida y fotografiada del conjunto de Lalibela es San Jorge (Figuras 3 у 4 ).

En el siglo XVI la capital etíope se traslada a Góndar. Es otro momento importante para el país, tras varios siglos de declive. Se convierte la ciudad en un importante centro cultural y artístico, así como en lugar de construcción de varios palacios e iglesias singulares. La corte recibió entonces a numerosas delegaciones europeas, procedentes fundamentalmente de Portugal debido al interés del país ibérico por controlar el paso comercial hacia la India, así como a misiones jesuíticas interesadas en divulgar el catolicismo frente al cristianismo ortodoxo imperante. Pero ninguna misión católica realmente fructificó y el país siguió aferrado a sus antiguas tradiciones y creencias.

En este contexto llegó a Etiopía el madrileño Pedro Páez como miembro de una misión jesuítica portuguesa. Nacido en el pueblo de Olmeda de las Fuentes (antes, y en época de Páez, Olmeda de la Cebolla), pronto descubrió su vocación religiosa, trasladándose a Lisboa. Desde aquí partiría para la India y, posteriormente, Etiopía. Pasa por ser el descubridor europeo de las fuentes del Nilo Azul (Guish Abbay), haciendo una descripción geográfica de la zona del máximo interés. Desde estas fuentes hasta el lago Tana (el mayor lago de Etiopía) al río se le conoce como Pequeño Nilo. Al sur el lago se desborda y da origen al Nilo Azul, atravesando de este a oeste el país hasta la frontera con Sudán y antes de desembocar en el Nilo Blanco en Jartum. Su caudal, que en tiempos proporcionaba abundante agua a las espectaculares cataratas de Tis Issat, hoy es utilizado para la producción hidroeléctrica gracias a la Gran Presa del Renacimiento Etíope. Esta presa es la mayor de África y ha sido causa de intensos enfrentamientos diplomáticos con Egipto por lo que representa de disminución del caudal final del Nilo.

Góndar, que fuera capital etíope en el s. XVI, es hoy una ciudad dinámica y bastante industrial, un polo económico con un dinamismo que rememora el que tuvo en tiempos en torno a una corte directamente influida por Europa a través de sus contactos diplomáticos. Se construyó entonces el recinto amurallado y un conjunto palaciego formado por seis edificios diferentes que albergaban al rey Fassilides, su corte y sus descendientes. Es la conocida como dinastía Fassilida. La imagen del recinto es espectacular porque trasciende el esquema mental que previamente se tiene de África y enlaza con las sólidas fortalezas medievales europeas (Figuras 5 y 6). 

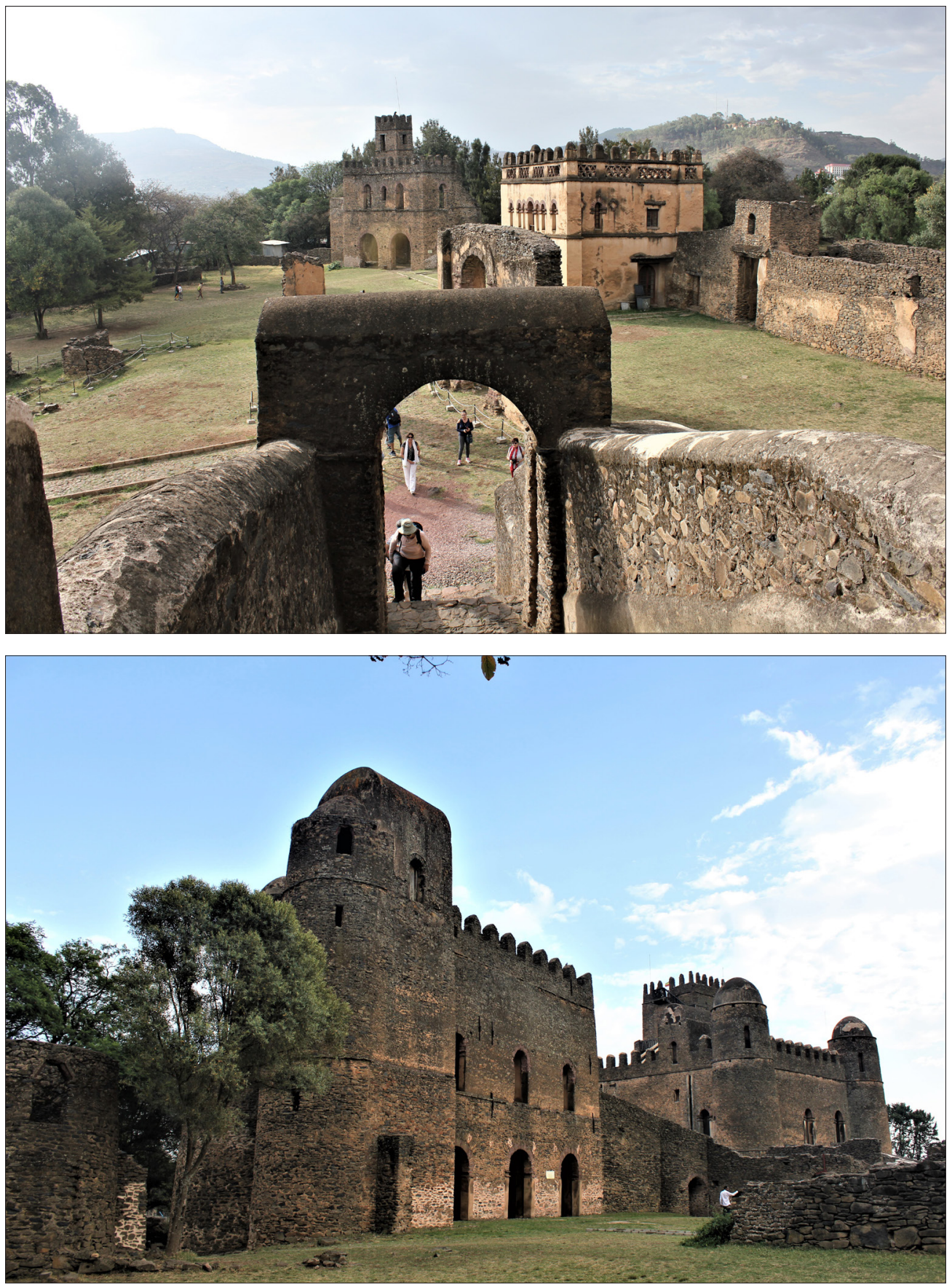

FIGURAS 5 y 6. CONJUNTO AMURALLADO Y PALACIEGo de Góndar. Fotografía del autor

La capitalidad de Góndar perduró hasta el siglo XIX, cuando se funda Addis Abeba en el centro del país. Esta fundación, a los pies del monte Entoto, fue estratégica y sirvió al Estado para extender el control político hacia el centro y sur de los actuales límites. Efectivamente, entonces Etiopía se lanzó a la carrera colonial conquistando, al igual que por entonces lo hicieron las principales potencias europeas en el continente, toda la mitad sur del país tal y como lo conocemos en nuestros días. 
De ahí, que en esta zona perviva aún la religión animista, las poblaciones sean típicamente negroides y se produzca casi una transición sin solución de continuidad con Kenia.

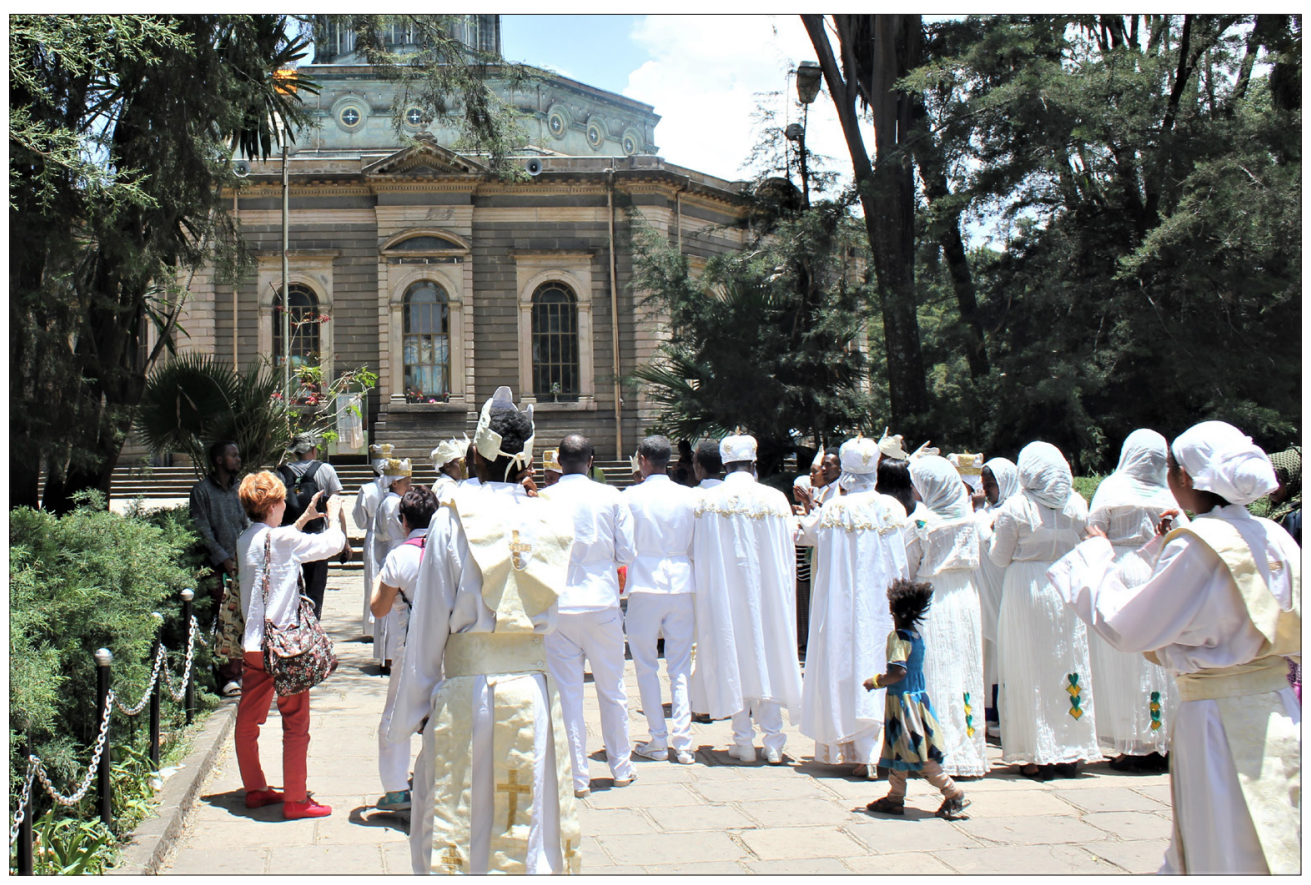

FIgURA 7. CATEDRAL DE SAN JORGE EN ADDIS ABEBA. Fotografía del autor

Esa conquista colonial hace aún más peculiar a este país. No solo no fue colonizado nunca por ninguna potencia europea (la presencia italiana en época de Mussolini fue corta, además de destructiva, y nunca Italia logró imponerse a la sociedad y cultura etíopes), sino que Etiopía se lanzó a la conquista desde el norte hacia el centro y sur, implantando la lengua amárica, las tradiciones y, solo parcialmente, la religión ortodoxa.

Addis Abeba es la capital de Etiopía y la capital de África, sede de la Unión Africana (Figuras 7 y 8). Una ciudad grande y desordenada, sin construcciones históricas de valor artístico e inmersa en una vorágine constructiva. Numerosos rascacielos están en marcha, así como barriadas periféricas de diseño moderno para acoger a la numerosa población inmigrante y sustituir a los extensos arrabales de autoconstrucción. Una dinámica que denota pujanza económica de un país con crecimiento desmedido, inversiones multimillonarias financiadas por China y sustentado políticamente por Estados Unidos como manera de controlar a la convulsa región del Cuerno de África. De hecho, Etiopía desempeña un papel determinante en la estabilización de esta parte del continente, jugó sus bazas en la desmembración de Sudán para que Sudán del Sur alcanzara su anhelada independencia, ha conseguido la paz definitiva con Eritrea tras una cruenta guerra antes y después de la escisión de este país, lo que sirvió al presidente etíope Abiy Ahmed Ali el Premio Nobel de la Paz en 20I9, y mantiene estrechos vínculos políticos y económicos con Yibuti para garantizar la salida comercial con 


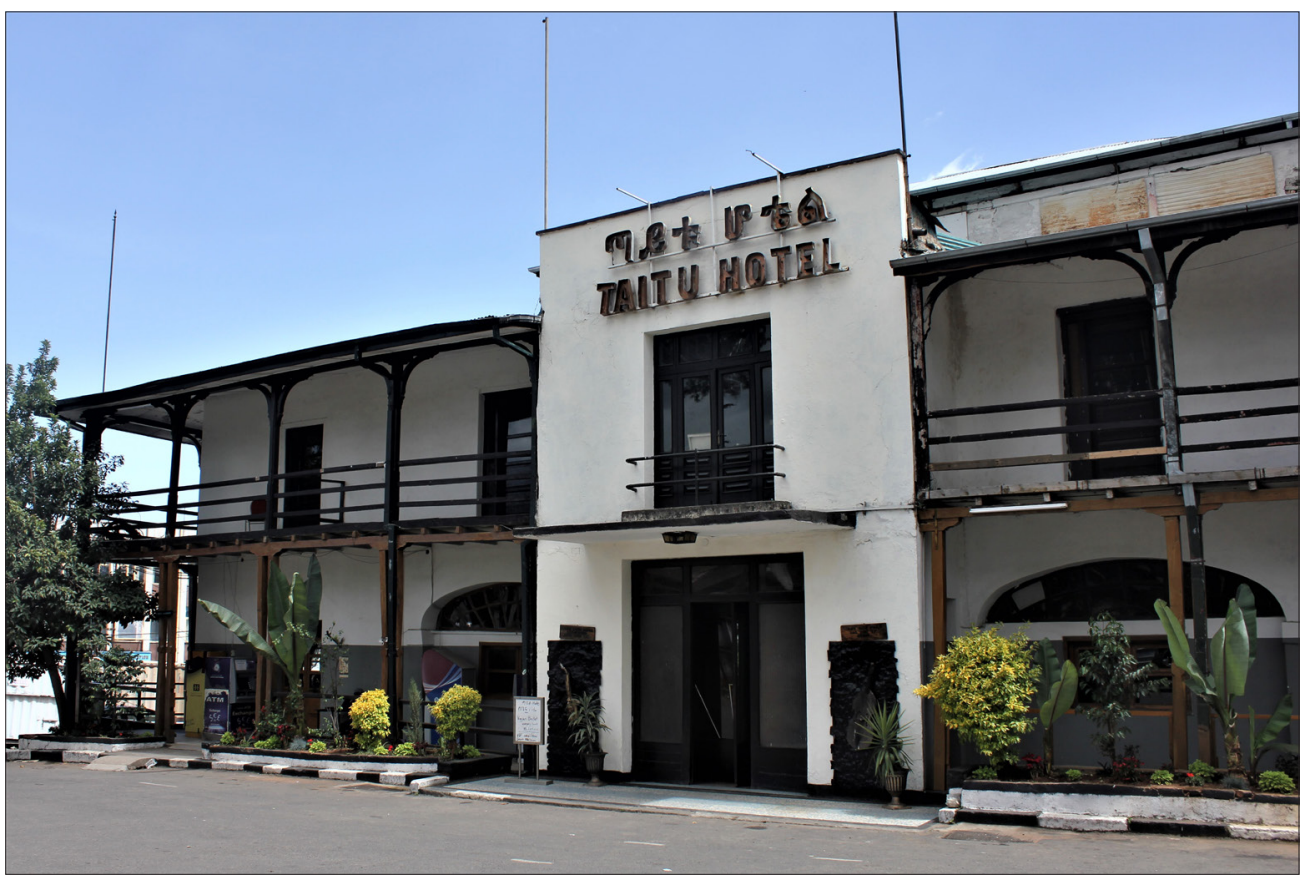

FIGURA 8. HOTEL TAITU EN ADDIS ABEBA, PRIMERA INSTALACIÓN TURÍSTICA DEL PAÍS CONSTRUIDA EN EL SIGLO XIX. Fotografía del autor

el mar Rojo y el Îndico, teniendo en cuenta que Etiopía se quedó sin costa ni puerto marítimo tras la independencia de Eritrea.

La frágil estabilidad política de Etiopía, país federal con fuertes tensiones nacionales dentro del variado conjunto de «naciones» que contempla su constitución, puede poner en riesgo los evidentes avances conseguidos en los últimos años. Aún queda mucho recorrido por hacer en el equilibrio inestable que caracteriza a un país diverso y variopinto. El progreso económico experimentado, concebido bajo una política desarrollista a ultranza al margen de consideraciones medioambientales, ha permitido al país alejarse, de momento, de las graves hambrunas que padeció en los años ochenta y noventa, símbolo entonces de los dramas humanitarios que aquejaban a todo un continente. 



\section{Presentación · Foreword}

\section{Artículos · Articles}

17 THOMAS BRASDEFER

Making space for freedom: The situationist Guide to protesting · Crear espacio

35 Carlos B. Buson; Carlos O. Zamberlan; Cláudia M. ${ }^{a}$ Sonaglio \& FABrícIo J. Missio

A proposta do caminho para os ervais: desenvolvendo territórios através da criação de itinerários culturais na fronteira Brasil-Paraguai . The Proposal of «Caminho para os Ervais»: Developing Territories through Creation of Cultural Itineraries in Brazil-Paraguay Border

55

Julia J. Carrero Espinosa y Pablo Martínez de Anguita

Hacia una ética del paisajismo

21 Concepción Fidalgo Hijano, Juan Antonio González Martín; Mario Corral Ribera; Rosario García Giménez \& Carlos Arteaga Cardineau Peatlands Evolution in Central Iberia (Montes de Toledo, Spain) and its Link to Anthropogenic Processes: A Cartography-Based Study . Evolución de las turberas en el centro de la Península Ibérica (Montes de Toledo) y su relación con los procesos

\section{Carlos Guallart Moreno}

La cartografía digital generada por la COVID-19: Análisis y tipologías . The

35 JuAn Guerra Guerra

Turismo de paisaje, desarrollo sostenible y ordenación del territorio en la isla de La Palma (Islas Canarias)

Territorial Planning in La Palma (Canary Islands)

\section{9}

\section{David Lacámara AYLón}

La ruptura de un equilibrio. El siglo XV y la paulatina ocupación y degradación de los espacios naturales zaragozanos

Milagros Mayoral Peñas; Beatriz Cristina Jiménez Blasco; Silvana Sassano luiz \& Rosa Resino García

Inmigración y educación: desigualdades y experiencias de discriminación en la Comunidad de Madrid

of Discrimination at Madrid's Community

215 Mercedes MilLán Escriche

La planificación como impulsora de la evolución socioeconómica y el desarrollo local de Torre Pacheco (Murcia)

\section{Evolution and Local Development of Torre Pacheco (Murcia)}

\section{4 Álvaro-Francisco Morote Seguido}

¿Cómo se trata el tiempo atmosférico y el clima en la Educación Primaria? Una exploración a partir de los recursos y actividades de los manuales escolares de Ciencias Sociales . How Weather and Climate is Treated in Primary Education? An Exploration from the Resources and Activities of Social Sciences Textbook

\section{José Ramón Sánchez Holgado \\ La aproximación a los restos arqueológicos de la batería de Varadero mediante el análisis de la cartografía. The Approach to the Archaeological Remains of the} Reseñas · Book Review

305 Hadjichambis, Andreas Ch.; Reis, Pedro; ParaskeVa-Hadjichambi, Demetra; ČınČERA, Jan; Boeve-de PAuw, Jelle; GerıCKE, Niklas; KNIPPELs, Marie-Christine (Eds.) (2020). Conceptualizing Environmental Citizenship for $21^{\text {st }}$ Century Education, Springer Open, 264 pág. ISBN: 978-3-030-20248-4 UOSÉ JESús DELGADO-PEÑA)

314

Martínez de Pisón, Eduardo (2019). Geografías y paisajes de Tintín. Viajes, lugares y dibujos, Madrid: Fórcola Ediciones, 187 pp. ISBN: 978-84-17425-36-4

315 Murga-Menoyo, M. ${ }^{a}$ A. y Bautista-Cerro, M. ${ }^{a}$ J. (Editoras) (2019). Guía PRADO. Sostenibilizar el currículo de la Educación Secundaria. Madrid: UNED. 422 págs Editorial. 162 pp. ISBN- $978-84-9080-762-8$

327 Reques Velasco, Pedro y Afonso, Luiekakio (2017). África como reto demográfico. Angola como paradigma. (Africa as a demographic challenge. Angola as a paradigm). Madrid: Casa África y Libros de la Catarata, 112 pp. ISBN: 97884-9097-278-6

\section{Imágenes y palabras • Pictures and Words}

333 Carlos J. PARdo Abad

Etiopía: recorrido por algunos paisajes naturales y culturales

Síntesis de Tesis Doctorales · Summaries of Doctoral Thesis

345 José Antonio GonzÁlez Díaz

Modelos de gestión del territorio, paisaje y biodiversidad en un espacio de montaña: la Reserva de la Biosfera de Redes, Departamento de Geografía de la Universidad de Oviedo. Directores/as: Dra. Rocío Rosa García \& Dr. Felipe Fernández García. Fecha de lectura: Julio 2019

\section{Alejandro Vallina Rodríguez}

Aspectos Naturales y culturales del paisaje de la Sierra de Guadarrama desde el análisis de su calidad visual. Departamento de Geografía. Universidad Autónoma de Madrid. Directora: Dra. Concepción Camarero Bullón. Fecha: 10 de julio de 2020

Historia de la Geografía española · History of Geography in Spain

36 Eva M. ${ }^{a}$ Martín-Roda Geografía y docencia en el legado del profesor José Estébanez Álvarez 
